\title{
Organophosphorus pesticide occurrence and distribution in surface and ground water of the United States, 1992-97
}

Water-quality data from surface- and ground-water samples were collected by the U.S. Geological Survey (USGS) National Water-Quality Assessment (NAWQA) Program and National Stream Quality Accounting Network (NASQAN) from 1992 to 1997. The data for selected organophosphorus pesticides (OPs) have been assembled into a geographic information system that is useful for evaluating the occurrence and distribution of $11 \mathrm{OPs}$ in rivers and aquifer systems within the United States. Analysis of these data indicate:
- OPs were detected more often and at higher concentrations in surface water than in ground water.

- In surface-water samples, diazinon, chlorpyrifos, and malathion were detected most often. The remaining OPs were detected less often and generally at lower concentrations.

- OPs were detected most often and at higher concentrations in small streams draining urban and some agricultural areas, and were occasionally detected as mixtures containing up to nine OPs.
- Chlorpyrifos was the most widely distributed OP in surface water, including a majority of the small streams draining urban or agricultural areas and some of the Nation's largest rivers.

- Median concentrations of OPs were well below the USEPA's Lifetime Health Advisories at all of the ground- and surface-water sites evaluated.

- Of the five OPs with aquatic-life criteria, the criterion for diazinon was exceeded most often.

-Aquatic-life criteria were exceeded most often in small urban streams.

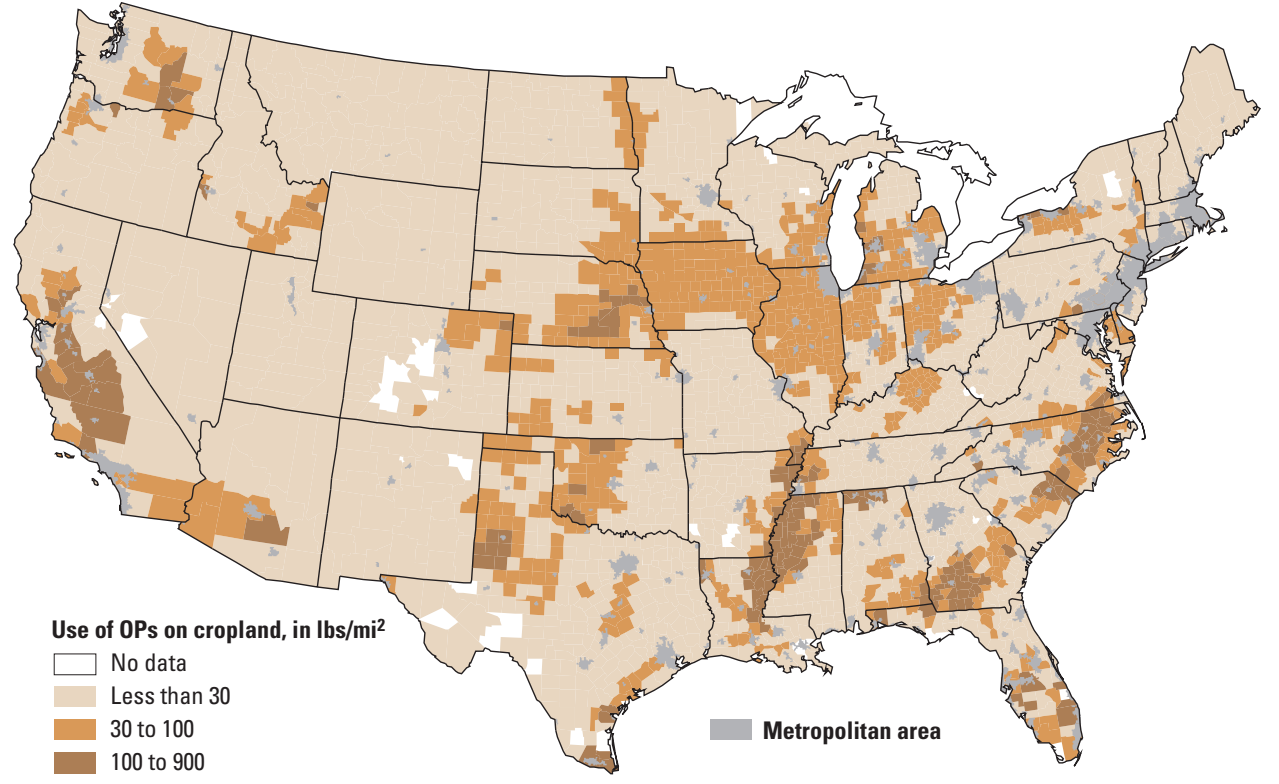

About 66 million pounds of organophosphorus pesticides (OPs) are used on cropland each year. Thirty-five OPs registered by the U.S. Environmental Protection Agency (USEPA) are used extensively on cropland in the United States for control of insects and related pests. Ten or more OPs are used in appreciable quantities on cropland in the irrigated valleys of the western United States, the lower Mississippi River Valley, and parts of the southeastern Coastal Plain. Estimates of OP use in the United States are conservative because they include only selected agricultural uses. Use information for many specialty crops is limited. No National information is available for non-cropland uses such as range and pasture land, turf and ornamentals, and structural pest control, but non-cropland uses may constitute much of the total use of some OPs.

\section{Introduction}

The USGS is investigating the occurrence and distribution of pesticides in water resources of the Nation as part of the NAWQA Program and NASQAN. The two programs differ somewhat in their scope, objectives, and implementation plans (Gilliom and others, 1995; Hooper and others, 1997). However, these programs share similar sampling protocols and pesticide analytical methods, and provide a relatively consistent basis for evaluating occurrence and distribution of a wide range of pesticides. This summary provides a brief description of the occurrence and distribution of 11 OPs in water resources of the United States. An accompanying CD-ROM presents water-quality data and associated information in a series of ArcView ${ }^{1}$ Projects and data bases that can be used to further evaluate current and future National OP data sets.

${ }^{1}$ Any use of trade, product, or firm names is for descriptive purposes only and does not imply endorsement by the U.S. Government. 
Pesticide data included in this report were collected in 1992-96 as part of the NAWQA Program and in 1996-97 as part of NASQAN and include about 3,700 surface-water samples and 3,000 groundwater samples. Additional information about the USGS National programs can be found at http:/water.usgs.gov/nawqa and http://water.usgs.gov/nasqan.

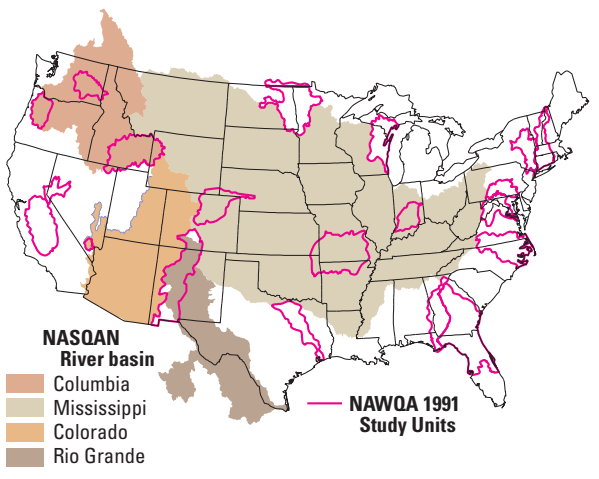

The NAWOA Program and NASOAN are evaluating the occurrence, distribution, and transport of pesticides in a large portion of the Nation's surface- and ground-water resources. The primary emphasis of the NAWOA Program is to relate surface- and ground-water quality to land use in approximately 59 study units located throughout the Nation. The emphasis of NASQAN is to estimate transport of sediment and dissolved chemical constituents in surface waters in the Nation's largest watersheds.

\section{Occurrence and distribution of OPs in surface water}

The occurrence and concentrations of OPs varied widely in surface-water samples collected as part of the NAWQA Program and NASQAN. Of the 11 OPs evaluated, chlorpyrifos, diazinon, and malathion were detected in the greatest percentage of samples and at the highest concentrations. Chlorpyrifos has more pounds of active ingredient applied to cropland than any other OP and was detected at more surface-water sites. Disulfoton, parathion, phorate, and terbufos were rarely detected. OPs were detected most often in samples from small streams draining urban areas and some agricultural areas. OPs were less prevalent in samples from rivers draining medium and large watersheds of mixed land use. In the 11 small urban watersheds studied, OPs used on turf, ornamentals, and for structural pest control were commonly detected. Diazinon was the most commonly detected OP, with percent detections ranging from 22 to 100 percent of samples from the 11 urban sites.
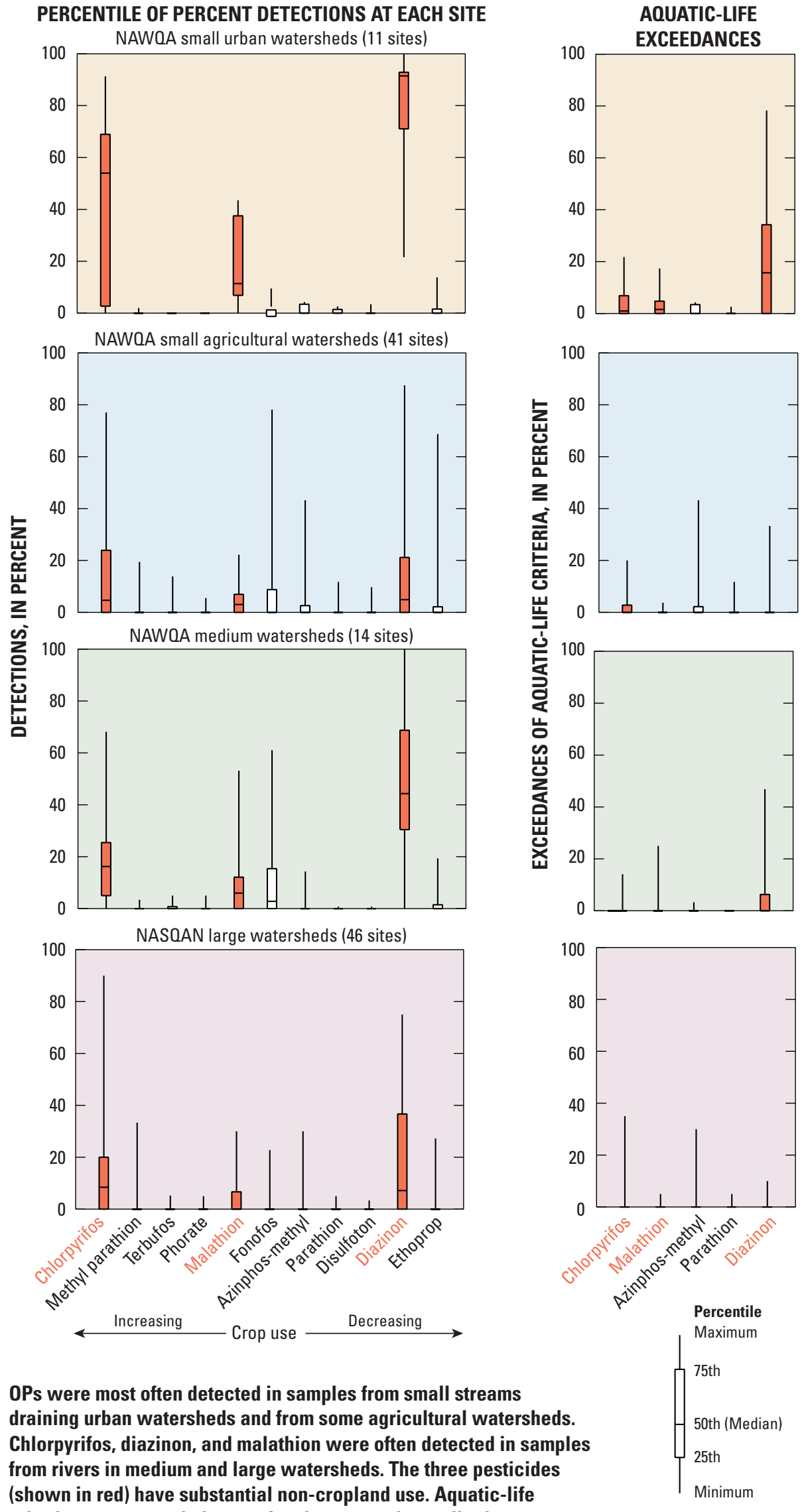

OPs were most often detected in samples from small streams draining urban watersheds and from some agricultural watersheds. Chlorpyrifos, diazinon, and malathion were often detected in samples from rivers in medium and large watersheds. The three pesticides (shown in red) have substantial non-cropland use. Aquatic-life criteria were exceeded most often in streams in small urban watersheds. Boxplots illustrate the distribution of percent detections (or percent aquatic-life exceedances) among sites. For example, the median percent detections of chlorpyrifos among the 46 NASQAN sites is $9 \%$; percent detections range from no detections at the Snake River at Burbank, Washington, to $90 \%$ detections at the Arroyo Colorado at Harlingen, Texas. Percentiles presented in this report are not adjusted for varied detection limits and sampling frequency. 
Analytical methods and quality-assurance procedures used by USGS waterquality programs provide consistent data sets for evaluating the occurrence and distribution of selected OPs in the Nation's water resources. Multianalyte methods developed by Zaugg and others (1995) have detection limits from 1 to 17 nannograms per liter. Median recoveries of spiked environmental samples ranged from 77 to 95 percent for the 11 OPs analyzed. The pesticide concentrations presented in this report may be considered conservative because results are from filtered samples and the determinations are not adjusted upward to compensate for recovery inefficiencies. Determinations of azinphos-methyl are considered estimates on the basis of low and highly variable recovery in laboratory and field spikes.
Chlorpyrifos and malathion also were commonly detected in urban streams (from 0 to 91 and from 0 to 43 percent of samples, respectively). Surface-water samples from the two small urban watersheds located in New England had fewer OPs and lower detection rates than samples from nine other urban watersheds located in the southern, midwestern, and western United States. This may be related to less use of OPs in urban areas in the northeast relative to other areas.

Each of the 11 OPs analyzed were detected in samples from streams draining small agricultural watersheds. Chlorpyrifos, diazinon, and malathion were all detected in samples from 26 of the 41 small agricultural watersheds.
Chlorpyrifos and diazinon were detected at the greatest frequency in small streams in agricultural areas located in the irrigated valleys of the western United States. Malathion was detected in a lower percentage of samples and was more broadly distributed throughout the United States. Although not widely distributed, azinphos-methyl and ethoprop were detected in 43 and 69 percent, respectively, of samples from a few small agricultural watersheds in western irrigated valleys.

\section{Occurrence and distribution of OPs in ground water}

OPs were rarely detected in ground-water samples analyzed as part of the NAWQA Program. Ground-water quality was not

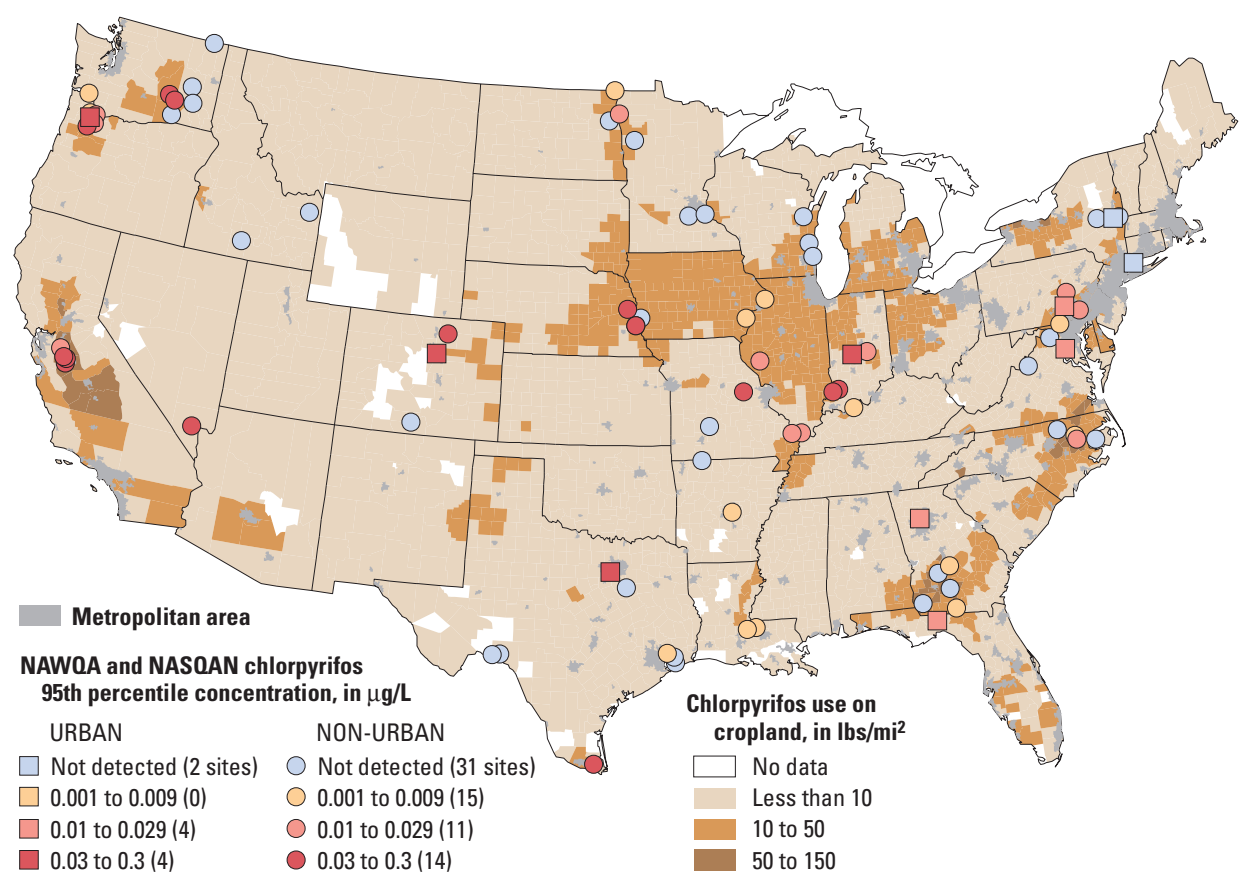

\section{Concentrations of $\mathrm{OPs}$ in relation to drinking-water guidelines}

Currently, there are limited human-health guidelines for evaluating OP occurrence in water resources and drinking water (Nowell and Resek, 1994). Seven of the OPs evaluated have chronic drinkingwater guidelines consisting of a USEPA Lifetime Health Advisory (HAL), a nonenforceable guideline for finished drinking water that is based on toxicity testing and includes a margin of safety. Median OP concentrations were well below HALs at all of the ground- and surface-water sites evaluated. Maximum sample concentrations of diazinon exceeded the HAL at nine NAWQA surfacewater sites, including four small streams draining urban areas, four small streams draining irrigated agricultural areas, and one medium-sized stream draining an area of mixed land use. Maximum concentrations for the other six OPs having HALs were below the respective advisories for all samples from surface- and groundwater sites evaluated.
Higher concentrations of chlorpyrifos are closely associated with urban areas and some agricultural areas. The ArcView Projects on the accompanying CD-ROM allow users to evaluate the occurrence and distribution of selected OPs in relation to pesticide use on cropland and other cultural and water-resource information. evaluated as part of NASQAN. Most detections of OPs in ground-water samples were near the analytical detection limits. ranged from 1.2 percent for diazinon to 0.1 percent or less for disulfoton, ethoprop, fonofos, methyl-parathion, parathion, detection and concentrations of the pestisamples, indicating that contamination must be considered in any analysis of
ground-water data for those compounds and possibly for other rarely detected analytes (Martin, and others, 1999).

\section{The USEPA has established drinking- water and aquatic-life guidelines for some, but not all of the OPs evaluated. Lifetime health advisories in drinking water have been established for 7
the 11 compounds evaluated; no maximum contaminant levels have freshwater aquatic-life criteria (am- by the USEPA or the International Joint Commission) exist for just five of the
compounds (Nowell and Resek, 1994).}




\section{Concentrations of $\mathrm{OPs}$ in relation to aquatic-life criteria}

Aquatic-life criteria have been compiled for 5 of the 11 OPs evaluated in this report (Nowell and Resek, 1994). They consist of USEPA chronic ambient water-quality criteria for freshwater aquatic life (four OPs) and an aquatic-life guideline for diazinon established by the International

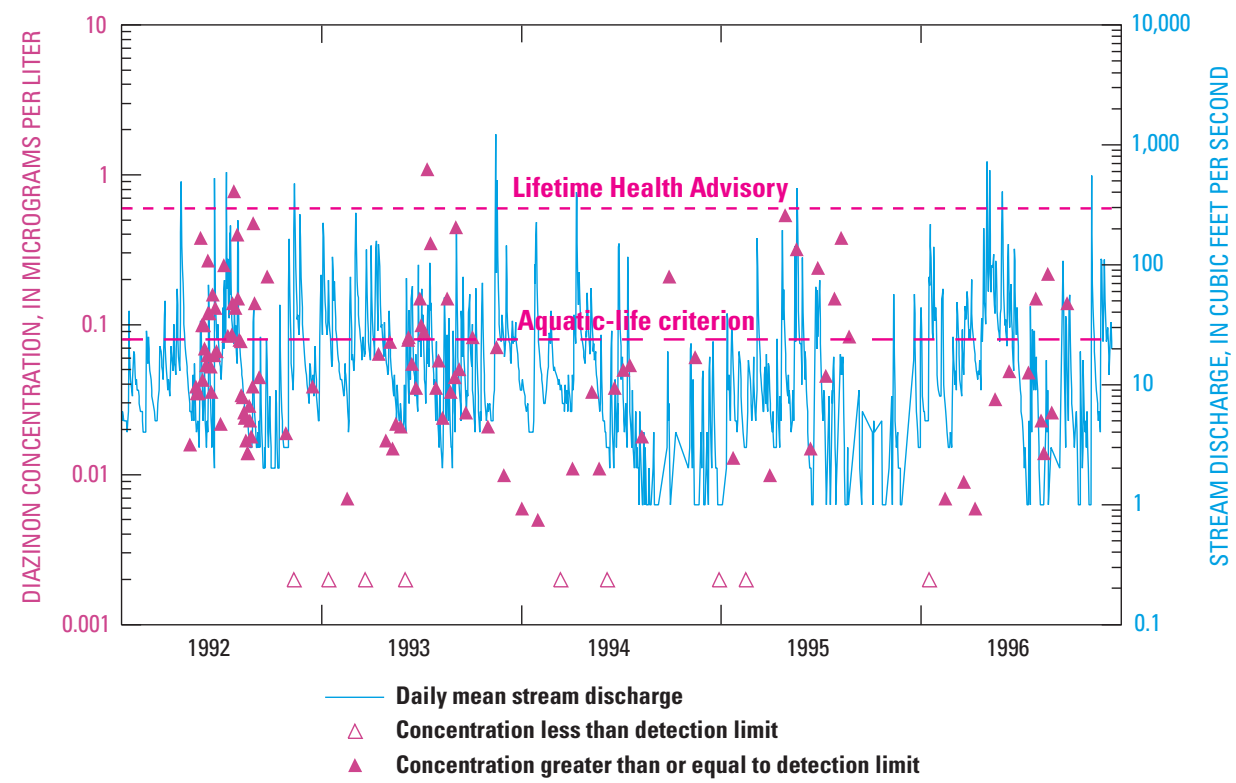

Temporal variation in diazinon concentrations in Little Buck Creek, a small urban stream near Indianapolis, Indiana. Concentrations of many OPs vary seasonally, with highest concentrations corresponding to the growing season (associated with applications) or wet seasons (associated with storm runoff).

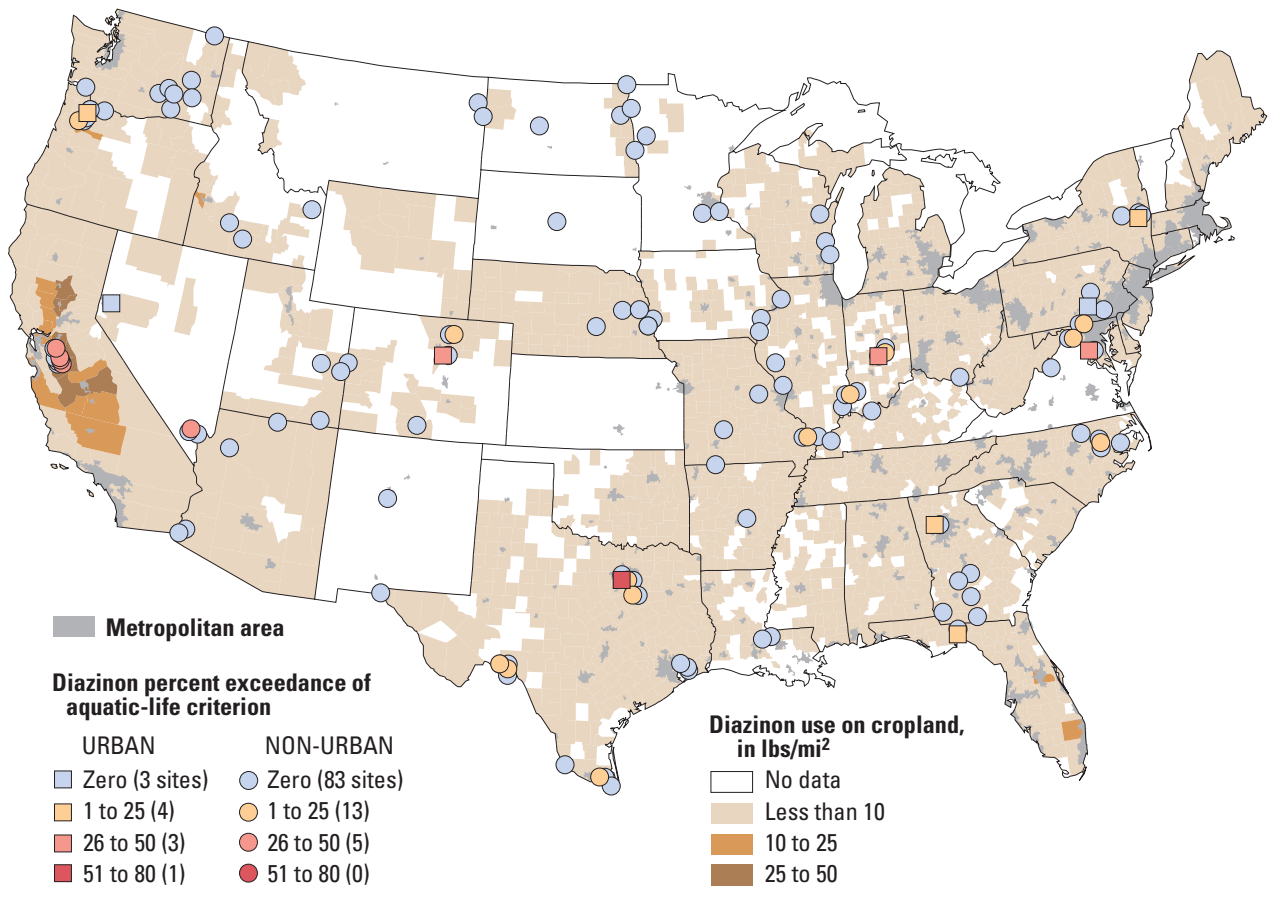

Concentrations of diazinon commonly exceeded a freshwater aquatic-life criterion in small urban watersheds and some agricultural watersheds.

\section{Selected references}

Gilliom, R.J., Alley, W.M., and Gurtz, M.E., 1995, Design of the National Water-Quality Assessment Program-Occurrence and distribution of water-quality conditions: U.S. Geological Survey Circular 1112, 33p. Available at URL http:// water.usgs.gov/pubs/circ/circ1112

Hooper, R.P., Goolsby, D.A., Rickert, D.A., and McKenzie, S.W., 1997, NASQAN-A program to monitor the water quality of the Nation's large rivers: U.S. Geological Survey Fact Sheet FS-055-97, 6p. Available at URL http:// water.usgs.gov/nasqan/natfact/ natfactsheet.html

International Joint Commission, 1977, New and revised Great Lakes water quality objectives, International Joint Commission Canada and United States, 155p.

Kolpin, D.W., Barbash, J.E., and Gilliom, R.J., 1998, Occurrence of pesticides in shallow ground water of the United States-Initial results from the National Water-Quality Assessment Program: Environmental Science \& Technology, v. 32, p. 558-566. Available at URL http:// water.wr.usgs.gov/pnsp/ja/est32

Larson, S.J., Gilliom R.J., and Capel, P., 1999, Pesticides in streams of the United StatesInitial results from the National Water-Quality Assessment Program: U.S. Geological Survey Water Resources Investigation Report 98-4222, 99p. Available at URL http://water.wr.usgs.gov/ pnsp/rep/wrir984222

Martin, J.D., Gilliom, R.J., and Schertz, T.L., 1999, Summary and evaluation of pesticides in field blanks collected for the National Water-Quality Assessment Program, 1992-1995: U.S. Geological Survey Open-File Report 98-412, 112p. Available at URL http://wwwrvares. er.usgs.gov/nawqa/protocols/doc_list.html

Nowell, L.H. and Resek, E.A., 1994, National standards and guidelines for pesticides in water, sediment, and aquatic organisms-Application to water-quality assessments, in Reviews in Environmental Contamination and Toxicology: New York, N.Y., Springer-Verlag, v. 140, 164p.

U.S. Geological Survey, 1999, The quality of our Nation's waters-Nutrients and pesticides: U.S. Geological Survey Circular 1225, 82p. Available at URL http://water.usgs.gov/pubs/ circ/circ1225

Zaugg, S.D., Sandstrom. M.W., Smith, S.G., and Fehlberg, K.M., 1995, Methods of analysis by the U.S. Geological Survey National Water Quality Laboratory-Determination of pesticides in water by $\mathrm{C}-18$ solid-phase extraction and capillary-column gas chromatography/mass spectrometry with selected-ion monitoring: U.S. Geological Survey Open-File Report 95-181, 49p. Available at URL http:// wwwnwql.cr.usgs.gov/Public/pubs/OFR95181/OFR 95-181.htm

\section{-By Evelyn H. Hopkins, Daniel J. Hippe, Elizabeth A. Frick, and Gary R. Buell}

\section{Acknowledgments}

The USGS acknowledges the USEPA Office of Pesticide Programs, Environmental Fate and Effects Division for their shared financial support of this data compilation and their constructive comments on the structure and functionalities of the GIS data bases. 